\title{
Emotional Eating Tendencies And General Health In Athletes: Gender Role
}

\author{
Emin Suel' ${ }^{1}$ Yusuf Soylu ${ }^{2}$ \\ ${ }^{1}$ Faculty of Sport Science, Nigde Omer Halis Demir University, \\ Nigde, Turkey \\ ${ }^{2}$ Faculty of Sport Science, Tokat Gaziosmanpasa University, \\ Tokat, Turkey
}

Study Area: Nigde, Turkey

Coordinates: $37^{\circ} 58^{\prime} \mathrm{oo}$ ?N; $34^{\circ} 40^{\prime} 45$ ?

Key words: Mood

\section{Abstract}

565 athletes from different branches $(\mathrm{F}=266, \mathrm{M}=299)$ participated in the study. Emotional Appetite Questionnaire (EMAQ), negative emotion (EMAQNE) and positive emotion (EMAQPE), Emotional Eater Questionnaire (EEQ) which consist three factors (Disinhibition, Type of food and Guilt), and General Health scale short form-12 (GH) were used in the study. According to the results, it was observed that there was a positive correlation between female athletes' Disinhibition, Type of Food, EEQ, and GH). There was a positive correlation between EMAQPE and Disinhibition, Type of Food, and GH. It was seen that there was a positive correlation between Disinhibition, Type of Food, Guilt, and EEQ and GH. When the correlation table of male athletes is examined, there was a positive correlation between EMAQNE and Disinhibition. Type of Food and EEQ, and Guilt and GH. We found that female athletes were sensitive to emotional eating in negative emotions compared to male athletes. It was thought that male and especially female athletes feel guilty after emotional eating behaviour and may have a negative impact on psychological processes.

occurs with negative psychological processes and triggers people to eat (Van Strien et al., 2017). Suel (2020) has stated that due to poor performance or a social problem emotional eating desire can reveal in athletes. Moreover, emotion regulation skills will be negatively affected by the desire to eat emotionally, resulting in decreased physical fitness or increased psychological problems in athletes (Devonport et al., 2020; Elfhag \& Rössner, 2005). In addition to staying away from psychologically negative situations (such as depression, anxiety), well-being may also be affected by mental, social, and physical health (Keyes, 2005; Huppert \& Whittington, 2003). When the literature is examined, general health status has been associated with psychological and mental processes such as mental disorders, anxiety, and depression (Weich et al., 2003, 2001).

The need to achieve optimal performance levels in athletes can also hurt athletic performance, personality traits, and mental health (Chang et al., 2020). With the influence of negative emotions, people often turn to foods high in calories during emotional eating and also increase the risk of cardiovascular and diabetes as weight balance changes (Elfhag \& Rossner, 2005). It is known that emotional eating and psychological general health status

*Corresponding Author:eminsuel51@yahoo.com 
are important for athletes, affecting their physical performance in competitions or training, and emotions have different effects according to gender. This study aimed to examine how the emotional eating and emotional appetite levels of athletes from different branches affect their general health in terms of gender.

\section{Materials and Methods:}

565 athletes (191 national athletes, 374 non-national athletes, 266 women, 299 men, 397 team athletes, 168 individual athletes, BMI of Female 20.91 \pm 2.55 BMI of male 23.39 \pm 6.14 ) from different branches participated in the study. It was filled in by the athletes using an online questionnaire along with an information form about the study.

Emotional Eating Questionnaire (EEQ): the questionnaire was developed by Garaulet et al., (2012) to determine the eating behaviors of overweight and obese people. Adapted into Turkish by Arslantas et al., (2019), the scale consisted of 10 questions and three sub-dimensions (disinhibition 5, type of food 3, and guilt 2), and the scoring type was (Never-o, Sometimes-1, Generally-2, and Always3). The highest score obtained from the scale indicated that emotional eating behavior was also high. The internal consistency coefficient of the scale was found to be .77 for Disinhibition, .66 for the Type of Food, and .61 for Guilt. In this study, the overall internal consistency coefficient of the scale was found to be $.84, .78$ for disinhibition, .64 for the type of food, and .72 for the guilt.

Emotional Appetite Questionnaire (EMAQ): EMAQ was developed by Nolan et al., (2010). Turkish adaptation of the scale was made by Demirel et al., (2014). The Cronbach Alpha coefficient of the scales was found to be .73. In this study, the internal consistency coefficient of the scale was found to be .82. Each item of the scale was scored as less (14 ), the same (5), and more (6-9), among 22 questions. The Questionnaire evaluated how emotional eating affects the person in negative/positive emotions (14 items) and negative/positive situations ( 8 items). When the scores for negative emotions and situations in the scale were added, the negative total score of the emotional appetite questionnaire and the positive total score of the emotional appetite questionnaire was obtained when the scores for positive emotions and situations were collected. The scale indicated in which emotions and situations eating can be dominant. In this study, only the positive/negative emotion part of the scale was used to determine which emotions lead the person to eat.

General Health Scale-12 (GHS-12): GHS-12 was stated that it can be used safely in determining the psychopathology level, mental states, psychiatric disorders, and non-psychotic depression and anxiety symptoms. It was developed by Goldberg \& Hiller (1979) and the scale had 12, 28, 30, and 6o questions forms. Turkish validity and reliability study of 12 and 28 question forms was conducted by Kilic (1996). The internal consistency coefficient of the scale was determined as .68. While each question was questioning the symptoms of the last 4 weeks, the items consisted of four options (never, as usual, more often than ever, very often). Two types of methods were used in the evaluation of the scale. In the first method, each item was given a score (o-1-2-3). In the second method, a scoring called GHS type (o-0-1-1) was used. A score of 2 or more in the GHS type scoring was considered to be mentally risky. It was accepted that the higher the score from the scale, meant the higher the risk of the disease. In this study, GHS type scoring was used.

SPSS 26 statistical program was used to analyze the data in the study. Kolmogorov-Smirnov and Shapiro-Wilk tests were used to determine whether the data were normally distributed. As a result of the analysis, it was determined that the data were distributed normally. Pearson's correlation analysis was used to examine the relationship between emotional eating, emotional appetite, and general health. Correlation coefficients were determined as .10-.30 weak, .40-.6o medium, .70-.90 strong, and 1 and above perfect (Dancey \& Reidy, 2007).

\section{Results:}

The differences between the emotional eating, emotional appetite scale negative/positive emotions, general health scales, and the gender of the athletes and the statistical information about the relationship between the general health scale, the emotional eating scale and its subdimensions, and the emotional appetite scale negative/positive emotions were included.

Table-1: EEQ, EMAQNE/PE, and General Health Correlation on Female Athletes

\begin{tabular}{llllllll}
\hline n=266 & 1 & 2 & 3 & 4 & 5 & 6 & 7 \\
\hline EMAQNE & 1 & $.137^{*}$ & $.492^{* *}$ & $.339^{* *}$ & .025 & $.499^{* *}$ & $.138^{*}$ \\
EMAQPE & & 1 & $.148^{*}$ & $.129^{*}$ & -.010 & $.132^{*}$ & $.140^{*}$ \\
Disinhibition & & 1 & $.58^{* *}$ & $.240^{* *}$ & $.955^{* *}$ & $.130^{*}$ \\
Type of Food & & & 1 & .105 & $.713^{* *}$ & $.139^{*}$ \\
Guilt & & & & & 1 & $.265^{* *}$ & $.418^{* *}$ \\
EEQtotal & \multirow{2}{*}{${ }^{*} \mathrm{p}<0.05 ;{ }^{* *} \mathrm{p}<0.01$} & & & 1 & $.161^{* *}$ \\
GH & & & & & & & 1 \\
\hline
\end{tabular}

A weak positive correlation between disinhibition with EMAQPE, the type of food, emotional eating total, and general health scales. Moreover, it was found that there was a positive moderate correlation between Emotional appetite scale positive emotions and disinhibition, type of food, emotional eating total and it was determined that there was a weak positive correlation between the general health scale. It was determined that there was a weak positive correlation between disinhibition, the type of food sub-dimensions and the general health scale, and the correlation between guilt sub-dimension and general health scale was found to be positively moderate. A weak 
ORIGINAL ARTICLE

positive correlation was found between the emotional eating scale total and the general health scale.

Table-2: EEQ, EMAQNE/PE, General Health Correlation Table of Male Athletes

\begin{tabular}{llllllll}
\hline $\mathrm{n}=299$ & 1 & 2 & 3 & 4 & 5 & 6 & 7 \\
\hline EMAQNE & 1 & $.195^{* *} .229^{* *}$ & $.202^{* *}$ & -.044 & $.248^{* *}$ & .059 \\
EMAQPE & 1 & -.032 & -.032 & -.010 & -.044 & .014 \\
Disinhibition & & 1 & $.500^{* *}$ & $.248^{* *}$ & $.914^{* *}$ & .084 \\
Type of Food & & & 1 & $.130^{*}$ & $.712^{* *}$ & .035 \\
Guilt & & & & 1 & $.237^{* *}$ & $.340^{* *}$ \\
EEQtotal & \multirow{2}{*}{${ }^{*} \mathrm{p}<0.05 ;{ }^{* *} \mathrm{p}<0.01$} & & 1 & .084 \\
GH & & & & & 1 \\
\hline
\end{tabular}

It was determined that there was a weak positive correlation between negative emotions and disinhibition and the type of food. It was observed that there was no relationship between EMAQPE and emotional eating and general health scale. A weak positive correlation was found between the emotional eating sub-dimension of guilt and the general health scale.

\section{Discussion:}

Physiological and psychological complexities that trigger eating disorders can disrupt physical and mental health (Anderson \& Petrie, 2012). Therefore, eating habits and emotional states can change the eating tendencies of athletes, moreover, they can affect the general health level. In this study, the relationship between emotional eating, which was one of the types of eating disorders in terms of gender and emotion interaction, and emotional eating tendencies in athletes and general health were examined.

In this study, when the relationship between the emotional eating tendencies of the team and individual female and male athletes and their general health levels was examined. According to female athletes results, there was a moderate positive relationship disinhibition with EMAQNE and emotional eating and a positive weak relationship with the type of food and EMAQPE. It was observed that there was a weak positive relationship between disinhibition, the type of food and emotional eating. It was determined that there was a weak positive relationship between disinhibition with EMAQNE and emotional eating, type of food and emotional eating of male athletes with EMAQNE. Lindeman \& Stark (2001) stated that emotional eating was generally associated with negative emotions. The sad mood was a determinant of emotional eating. (Kornacka et al., 2020). Van Strien et al., (2013) stated that overweight people eating as a coping strategy against stress and negative emotions. SundgotBorgen \& Torstveit (2004) emphasized that female athletes had higher eating disorders than men in the study, which was one of the most comprehensive studies on eating disorders and comparing different types of eating disorders. Researchers (Larsen et al., 2006; van Strien, 2005) was stated that women's emotional eating levels were
Ambient Science, 2020: Vol. 07(Sp1); 170-175 DOI:10.21276/ambi.2020.07.sp1.oa21

high. Kenardy et al., (2003) examined the emotional relationship between male and female before eating and after eating, and it was found that female's negative and positive moods before eating caused an increase in a positive mood after eating. He also stated that there was a decrease in the negative mood of males after meals, but females were more emotionally prone to eating. Similarly, Macht et al., (2004) found that generally negative emotions trigger eating as well as positive emotions. In other studies in the literature (Joy et al., 2016; Varnes et al., 2013), it was stated that the risk of eating disorders was higher in female athletes compared to male athletes and non-athletes women. In the current study, when the relationship of female athletes and male athletes with emotional eating was examined, the results show that female athletes had a higher relationship with emotional eating than men. It was found that negative emotions direct male athletes to eat, but female athletes were more susceptible to eating more than negative emotions while encouraging them to eat with positive emotions. It can be said that the emergence of the urge to eat in both positive and negative emotions was due to the lack of emotion regulation skills of female athletes. Researchers have reported that people with emotion regulation skills have the ability to accurately describe and change emotional experience. (Aldao \& Nolen-Hoeksema, 2010; Grantz \& Roemer, 2004). Researchers (Leppanen et al., 2018; Medina-Pradas et al., 2012) stated that lack of emotion recognition was associated with eating disorders. Shriver et al., (2016) stated that athletes who were inadequate in emotion regulation were more frequently exposed to eating disorders.

In this study, the relationship between EMAQNE, EMAQPE, emotional eating and general health of female and male athletes were examined. According to the results of the study, a weak relationship was found between feelings of guilt and general health in the emotional eating sub-dimension of male athletes. It was observed that there was a weak relationship between negative/positive emotions, disinhibition with EMAQNE and emotional eating, type of food and emotional eating total and general health of female athletes. However, it was found that there was a moderate relationship between the guilt subscale and general health. The concept of emotional eating emerged with the psychosomatic theory (Bruch, 1964), the difference between physiologically felt hunger and hunger caused by negative emotions was not noticed by emotional eaters. (Adriaanse et al., 2011). While Greeno \& Wing (1994) generally negative emotions should create a physiological environment that makes people feel full, emotional eaters tend to eat when they encounter negative emotions. Different researchers were stated that depression poses a high risk in conditions such as increased appetite, weight gain, and obesity (DSM-5; American Psychiatric Association, 2013; Luppino et al., 2010; Blaine, 2008). 
However, Strien et al., (2016) stated that emotional eating had a higher mediating effect on depression and body mass index in women compared to men. Similarly, Suel (2020) stated that female basketball players had higher levels of disinhibition with EMAQNE and emotional eating, type of food, guilt, and emotional eating compared to men. van Strien (2005) stated that women tend to eat emotionally more than men. Lazarevich et al., (2016) stated that emotional eating had a mediating effect between depression and BMI, and it constitutes a significant part of this indirect effect with women (25.0\%) and men (23.1\%). Similarly, previous studies (Clum et al., 2014; Goldschmidt et al., 2014) emphasized that there was a mediating effect between emotional eating, depression, and future weight gain. Again, van Strien et al., (2016) found that emotional eating behaviors in women had a mediator effect between depression and BMI. Lazarevich et al., (2016) emphasized that the effect of depression on motivation to eat can be both positive and negative, however, melancholic depression may decrease or increase appetite and a distinction should be made between depression with atypical characteristics that provide appetite increase. It was the relationship between feelings of guilt and general health that had an important place in our study for both female and male athletes. Although the relationship between feelings of guilt and general health was weak in men, it was medium in women. Bennett et al., (2013) stated that stress was one of the primary triggers for emotional eating, and at the same time, guilt emerges after eating behavior. In addition, after emotional eating behavior, women stated that they felt more guilt than men. Similarly, Wallis \& Hetherington (2009) found that women felt more guilty after certain foods. Hurst et al., (2017) stated that the introverted regulation caused by the feeling of guilt or embarrassment may be associated with the body image of women and exercise goals. As seen in the literature, female athletes feel more negative psychological events than men, leading to emotional eating tendencies.

When the literature was examined as the limitations of the study, studies on emotional eating and emotions were obese people, diabetes patients, or university students. There were no studies examining the relationship between athletes' (especially gender role) emotional eating, negative/positive emotions, and general health. According to the results of our study, the relationship between negative emotions and emotional eating of male athletes showed a weak relationship. But it turned out that this situation was higher in female athletes. Felt of guilt after emotional eating affected the psychological processes of female and male athletes. How this effect will affect mental or physical performance should be revealed by future studies.

\section{References:}

Adriaanse, M.A., de Ridder, D.T. \& Evers, C. (2011): Emotional eating: eating when emotional or emotional about eating?
Psychol. E Health, 26(1):23-39.

Aldao, A. \& Nolen-Hoeksema, S. (2010): Specificity of cognitive emotion regulation strategies: a transdiagnostic examination. Behav. Res. Ther., 48(10):974-983.

American Psychiatric Association. (2013): Diagnostic and statistical manual of mental disorders ( 5 th ed.). Pub. by: Washington, DC: American Psychiatric Pub.

Anderson, C. \& Petrie, T.A. (2012): Prevalence of disordered eating and pathogenic weight control behaviors among NCAA division I female collegiate gymnasts and swimmers. Res. Quart. Exer. Sport, 83(1):120-124.

Arslantas, H., Dereboy, F., Yuksel, R. \& Inalkac, S. (2020): Validity and Reliability of the Turkish Version of the Emotional Eater Questionnaire (EEQ-TR). Turk Psikiyatri Dergisi, 31(2):12230.

Bangsbo, J. (2008): Entrenamiento de la condición física en el fútbol. Pub. by: Barcelona: Paidotribo.

Bennett, J., Greene, G. \& Schwartz-Barcott, D. (2013): Perceptions of emotional eating behavior. A qualitative study of college students. Appetite, 6o(1):187-192.

Blaine, B. (2008). Does depression cause obesity? A meta-analysis of longitudinal studies of depression and weight control. $L$. Health Psychol., 13(8):119oen197.

Bratland-Sanda, S. \& Sundgot-Borgen, J. (2013): Eating disorders in athletes: Overview of prevalence, risk factors and recommendations for prevention and treatment. Eu. J. Sport Sci., 13(5):499-508.

Bruch, H. (1964): Psychological aspects of overeating and obesity. Psychosomatics, 5:269-274.

Chang, C., Putukian, M., Aerni, G., Diamond, A., Hong, G., Ingram, Y., Reardon, C.L. \& Wolanin, A. (2020): Mental health issues and psychological factors in athletes: detection, management, effect on performance and prevention: American Medical Society for Sports Medicine Position Statement-Executive Summary. Br. J. Sports Med., 54(4):216220.

Clum, G.A., Rice, J.C., Broussard, M., Johnson, C.C. \& Webber, L.S. (2014): Asso- ciations between depressive symptoms, selfefficacy, eating styles, exercise and body mass index in women. L. Behav. Med., 37:577e586.

Dancey, C.P. \& Reidy, J. (2007): Statistics without maths for psychology. Pub. by: Pearson education.

De Bruin, A.P., Oudejans, R.D.D. \& Bakker, F.C. (2007): Dieting and body image in aesthetic sports: a comparison of Dutch female gymnasts and non-aesthetic sport participants. Psychol. Sport Exer., 8:507-520.

Demirel, B., Yavuz, F.K., Karadere, M.E., Safak, Y. \& Turkcapar, M.H. (2014): Duygusal Istah Anketi'nin Türkçe geçerlik ve güvenilirligi, beden kitle indeksi ve duygusal semalarla iliskisi. JCBPR, 3:171-181.

Devonport, T.J., Nicholls, W. \& Chen-Wilson, C. (2020): Emotional Eating: Implications for Research and Practice in Elite Sports Contexts. Ruiz MC, Robazza C (Eds.). (2020). Feelings in Sport: Theory, Research, and Practical Implications for Performance and Well-being, Pub. by: Routledge, New York. 


\section{ORIGINAL ARTICLE}

Elfhag, K. \& Rössner, S. (2005): "Who succeeds in maintaining weight loss? A conceptual review of factors associated with weight loss maintenance and weight regain." Obes. Rev., 6(1):67-85.

Garaulet, M., Canteras, M., Morales, E., et al. (2012): Validation of a questionnaire on emotional eating for use in cases of obesity; the Emotional Eater Questionnaire (EEQ). Nutr. Hosp., 27:645-51.

Goldberg, David, P., Valerie, F. \& Hillier. (1979): A scaled version of the General Health Questionnaire. Psychol. Med., 9(1):139145 .

Goldschmidt, A.B., Crosby, R.D., Engel, S.T., Crow, S.J., Cao, L., Peterson, C.B., et al. (2014): Affect and eating behavior in obese adults with and without elevated depression symptoms. Int. J. Eat. Disor., 47(3):281e286.

Gratz, K.L. \& Roemer, L. (2004): Multidimensional assessment of emotion regulation and dysregulation: development, factor structure, and initial validation of the difficulties in emotion regulation scale. J. Psychopathol. Behav. Asses., 26:41-54.

Greeno, C.G. \& Wing, R.R. (1994): Stress-induced eating. Psychol. Bull., 115(3):444-464.

Huppert, F.A. \& Whittington, J.E. (2003): Evidence for the independence of positive and negative well-being: implications for quality of life assessment. Br. J. Health Psychol., 8(1):107-22.

Hurst, M., Dittmar, H., Banerjee, R. \& Bond, R. (2017): "I just feel so guilty": The role of introjected regulation in linking appearance goals for exercise with women's body image. Body Image, 20:120-129.

Joy, E., Kussman, A. \& Nattiv, A. (2016): 2016 update on eating disorders in athletes: A comprehensive narrative review with a focus on clinical assessment and management. Br. J. Sports Med.,50(3):154-162.

Kenardy, J., Butler, A., Carter, C. \& Moor, S. (2003): Eating, mood, and gender in a noneating disorder population. Eating Behav., 4(2):149-158.

Keyes, C.L. (2005). Mental illness and/or mental health? Investigating axioms of the complete state model of health. $J$. Consult Clin. Psychol., 73(3):539-48.

Kilic, C. (1996): Genel saglik anketi: Güvenilirlik ve geçerlilik çalismasi. Türk Psikiyatri Dergisi., 7(1):3-10.

Kornacka, M., Czepczor-Bernat, K., Napieralski, P. \& BrytekMatera, A. (2020): Rumination, mood, and maladaptive eating behaviors in overweight and healthy populations. Eat Weight Disor.

Larsen, J.K., van Strien, T., Eisinga, R. \& Engels, R.C. (2006): Gender differences in the association between alexithymia and emotional eating in obese individuals. J. Psychosom. Res., 60(3):237-243.

Lazarevich, I., Irigoyen Camacho, M.E., Velázquez-Alva, M. \& Zepeda Zepeda, M. (2016): Relationship among obesity, depression, and emotional eating in young adults. Appetite, 107:639-644.

Lindeman, M. \& Stark, K. (2001): Emotional eating and eating disorder psychopathology. Eat. Disor., 9(3):251-259.

Luppino, F.S., de Wit, L.M., Bouvy, P.F., Stijnen, T. \& Cuijpers, P.
Ambient Science, 2020: Vol. 07(Sp1); 170-175 DOI:10.21276/ambi.2020.07.sp1.oa21

(2010): Overweight, obesity, and depression a systematic review and meta-analysis of longitudinal studies. Arch. Gen. Psych., 67(3):220e229.

Macht, M., Haupt, C. \& Salewsky, A. (2004): Emotions and eating in everyday life. Application of the experience-sampling method. Ecol. Food Nut., 43(4):11-21.

Marini, E., Campa, F., Buffa, R., Stagi, S., Matias, C.N., Toselli, S., Sardinha, L.B. \& Silva, A.M. (2020): Phase angle and bioelectrical impedance vector analysis in the evaluation of body composition in athletes. Clinic. Nutr., 39(2):447-454.

Markser, V.Z. (2011): Sport psychiatry and psychotherapy. Mental strains and disorders in professional sports. Challenge and answer to societal changes. Eu. Arc. Psychiat. Clinic. Neurosci., 261:182-185.

McGill, S.M., Andersen, J.T. \& Horne, A.D. (2012): Predicting performance and injury resilience from movement quality and fitness scores in a basketball team over 2 years. J. Strength Condition. Res., 26(7):1731-1739.

Nolan, L.J., Halperin, L.B. \& Geliebter, A. (2010): Emotional appetite questionnaire.Construct validity and relationship with BMI. Appetite, 54(2):314-319.

Sahin, I. (2020): The relationship between emotional eating and mindfulness among wrestlers. Prog. in Nutr., 22(2S):e2020010.

Schaal, K., Tafflet, M., Nassif, H., Thibault, V., Pichard, C., Alcotte, M., Guillet, T., Helou, N.E., Berthelot, G., Simon, S. \& Toussaint, J.F. (2011): Psychological balance in high level athletes: gender-based differences and sport-specific patterns. PLoSONE, 6(5):e19007.

Shriver, L.H., Wollenberg, G. \& Gates, G.E. (2016): Prevalence of disordered eating and its association with emotion regulation in female college athletes. Int. J. Sport Nutr. Exer. Metabol., 26(3):240-248.

Smolak, L., Murnen, S.K. \& Ruble, A.E. (2000): Female athletes and eating prob-lems: a meta-analysis. Int. J. Eat Disor., 27:371-380.

Suel, E. (2020): The relationship between emotional eating and general health among professional basketball players. Prog. Nut., 22(2-S):e2020020.

Sundgot-Borgen, J. \& Torstveit, M.K. (2004): Prevalence of eating disorders in elite athletes is higher than in the general population. Clinic. J. Sport Med., 14(1):25-32.

van Strien, T., Cebolla, A., Etchemendy, E., Gutiérrez-Maldonado, J., Ferrer-García, M., Botella, C. \& Banos, R. (2013): Emotional eating and food intake after sadness and joy. Appetite, 66:2025 .

van Strien, T., Winkens, L., Toft, M.B., Pedersen, S., Brouwer, I., Visser, M. \& Lähteenmäki, L. (2016): The mediation effect of emotional eating between depression and body mass index in the two European countries Denmark and Spain. Appetite, 1(105):500-8.

van Strien, T. (2005): Handleiding Nederlandse Vragenlijst voor Eetgedrag [Manual Dutch Eating Behavior Questionnaire]. Pub. by:Amsterdam: Boom Test Publishers.

Varnes, J.R., Stellefson, M.L., Janelle, C.M., Dorman, S.M., Dodd, V. \& Miller, M.D. (2013): A systematic review of studies comparing body image concerns among female college 
athletes and non-athletes, 1997-2012. Body image, $10(4): 421-432$.

Wallis, D.J. \& Hetherington, M.M. (2009): Emotions and eating. Self-reported and experimentally induced changes in food intake under stress. Appetite, 52(2):355-362.

Weich, S., Holt, G., Twigg, L., Jones, K. \& Lewis, G. (2003): Geographic variation in the prevalence of common mental disorders in Britain: a multilevel investigation. Am. J. Epidemiol., 157(8):730-7.
Weich, S., Lewis, G. \& Jenkins, S.P. (2001): Income inequality and the prevalence of common mental disorders in Britain. Br.J. Psychiatry, 178:222-7. 